\title{
Abnormal Glucose Metabolism in Rheumatoid Arthritis
}

\author{
Hui Pi, ${ }^{1}$ Haotong Zhou, ${ }^{1}$ Huan Jin, ${ }^{1}$ Yaogui Ning, ${ }^{2}$ and Youlian Wang ${ }^{1}$ \\ ${ }^{1}$ Department of Rheumatology, Jiangxi Provincial People's Hospital, Nanchang 330006, China \\ ${ }^{2}$ Department of Critical Care Medicine, The First Affiliated Hospital of Xiamen University, Xiamen 361003, China \\ Correspondence should be addressed to Yaogui Ning; ningyaogui@stu.xmu.edu.cn and Youlian Wang; wyl5639@sina.com
}

Received 22 November 2016; Accepted 9 April 2017; Published 26 April 2017

Academic Editor: Brant R. Burkhardt

Copyright (C) 2017 Hui Pi et al. This is an open access article distributed under the Creative Commons Attribution License, which permits unrestricted use, distribution, and reproduction in any medium, provided the original work is properly cited.

\begin{abstract}
The incidence of abnormal glucose metabolism in patients with rheumatoid arthritis was considerably higher than the general population. The persistent systemic inflammatory state in rheumatoid arthritis might be associated with the glucose metabolism dysfunction. In this context, insulin resistance, islet $\beta$ cell apoptosis, inflammatory cytokines, and other aspects which were linked with abnormal glucose metabolism in rheumatoid arthritis were reviewed. This review will be helpful in understanding the abnormal glucose metabolism mechanism in patients with rheumatoid arthritis and might be conducive to finding an effective treatment.
\end{abstract}

\section{Introduction}

Rheumatoid arthritis (RA) is a systemic autoimmune disease characterized by chronic, symmetry, and destructive poly-articular synovitis. Although its pathogenesis remains unclear, it has shown that inflammation induced by abnormal immune response plays a crucial role in the development of RA. Recent studies show that RA patients with diabetes mellitus (DM) prevalence rate was about $15 \%$ to $19 \%$, which was significantly higher than the prevalence rate of $4 \%$ to $8 \%$ of global middle-aged population DM $[1,2]$. In a study, which consists of 48,718 cases of RA patients and 40,346 cases of nonrheumatic subjects, the incidence of RA patients with DM was $0.86 \%$ higher than the $0.58 \%$ in the control group which were observed, and DM risk was 1.5-fold in RA patients when compared with control group [3]. Consistently, a study described that abnormal glucose metabolism in RA patients was up to $46 \%$ after 2 years when compared with the time point of recruitment [4]. It is seen that the impaired glucose metabolism may be accelerated progress in RA patients. Here, the abnormal glucose metabolism in RA patients was reviewed.

\section{Inflammation and Abnormal Glucose Metabolism}

2.1. Inflammation and Insulin Resistance (IR). Proinflammatory cytokines (TNF- $\alpha$, IL-6, etc.) are closely associated with IR, and its possible mechanisms include the following: (1) TNF- $\alpha$ inhibits the cascade effect of insulin signaling pathway and insulin signaling pathway through stimulating insulin receptor substrate-1 (IRS-1) phosphorylation of serine which inhibited tyrosine phosphorylation [5], reduces adipocyte glucose transport protein-4 (GLUT4) expression, and inhibits the generation of adiponectin and resistances the effect of adiponectin promote insulin sensitivity [6]; (2) TNF- $\alpha$ and IL- 6 can accelerate lipolysis and improve the level of free fatty acids which was an important factor in participation in the development of IR [7]; (3) IL- $1 \beta$ reduces the expression of IRS-1 leading to impaired insulin signal transduction through an extracellular signal-regulated kinase at the transcriptional level but not a posttranscriptional pathway [8]; (4) As an anti-inflammatory cytokine, low levels of IL-10 in the human exert an insulin-sensitizing effect [9].

2.2. Inflammation and $\beta$ Cell Dysfunction and Apoptosis. Studies have demonstrated that the insulin secretion of islet $\beta$ cells stimulated by glucose was inhibited when the IL- $1 \beta$, IFN- $\gamma$, and TNF- $\alpha$ were added in the islet $\beta$ cells culture system [10]. Furthermore, IL-1 $\beta$ treatment can stimulate inducible nitric oxide synthase (iNOS) expression resulting in an increased production of $\mathrm{NO}$ and a decreased intracellular electron transfer mitochondrial ATP synthesis. Intracellular ATP content could inhibit the secretion of insulin, leading to $\beta$ cell dysfunction [11]. Besides, the increased Fas/FasL 
expression of $\beta$ cells would lead to cell apoptosis [12]. NF$\kappa \mathrm{B}$, the mainly downstream regulator in pancreatic $\beta$ cell stimulated by inflammatory cytokines, inhibits production of $\beta$ cell specific proteins, such as insulin, glucose transporter 2 (GLUT-2), and insulin promoter-1 and promotes iNOS production [13]. In the meantime, it has been shown that sulforaphane exhibits a preventive role in the cytokine-induced $\beta$ cell insulin secretory dysfunction and apoptosis through inhibiting NF- $\kappa$ B activation and iNOS production [14].

Apoptosis mediated by endoplasmic reticulum stress has been proved to be one of the important mechanisms in pancreatic $\beta$ cell apoptosis induced by IL- $1 \beta$. Combination of IL- $1 \beta$ and IFN- $\gamma$ treatment can significantly reduce the sarcoplasmic reticulum calcium pump ATP enzyme $2 \mathrm{~b}$ protein expression and consumption endoplasmic reticulum $\mathrm{Ca}^{2+}$ storage, which also is raised by the $\mathrm{BH} 3$-only protein (only a proapoptotic protein $\mathrm{Bcl}-2$ homology domain, belonging to $\mathrm{Bcl}-2$ family) through inducing NO synthesis [15]. Islet $\beta$ cells with 4-phenyl butyrate treatment significantly reduced the cell endoplasmic reticulum stress and cell apoptosis, which was induced by IL- $1 \beta$ through regulating endoplasmic reticulum $\mathrm{Ca}^{2+}$ concentration and $\mathrm{c}$-Jun-terminal kinase (JNK) signaling pathway activation [16]. Interestingly, IL1 receptor antagonist (IL-1ra) treatment can significantly improve blood sugar, glycated hemoglobin, proinsulin, and insulin and pancreatic $\beta$ cell function in the diabetic mice induced by high-fat diet. Besides, it also reduced pancreatic $\beta$ cells apoptosis, increased proliferation of $\beta$ cells, and improved glucose-induced insulin secretion in vitro $[17,18]$.

The combination of IFN- $\gamma$ and TNF- $\alpha$ treatment promoted the islet $\beta$ cells classic cysteine-dependent apoptosis, while the administration of TNF- $\alpha$ alone did not increase islet $\beta$ cells apoptosis. The mechanism might be due to the expression of NF- $\kappa$ B upregulated by TNF- $\alpha$ stimulation which exhibited an antiapoptotic effect. However, the NF- $\kappa \mathrm{B}$ activation induced by IFN- $\gamma$ or IL- $1 \beta$ was considered as a proapoptotic modulator [19]. Previous studies also demonstrated that combination of IFN- $\gamma$ and TNF- $\alpha$ treatment did not increase apoptosis in the signal transducer and activator of transcription-1 (STAT1) transfected-pancreatic $\beta$ cell, which revealed that STAT1 played an essential role in inhibiting $\beta$ cell apoptosis resulting from IFN- $\gamma$ and TNF- $\alpha$ treatment [20].

2.3. Rheumatoid Arthritis, Inflammation, and Insulin Resistance. Inflammatory cytokines, such as TNF- $\alpha$, IFN- $\gamma$, IL6 , and IL-1 $\beta$, play a crucial role in the development of RA [21], and blockage of these cytokines' activity was applied in clinical therapy $[22,23]$. Biologic therapies that target specific inflammatory cytokines could improve outcomes of RA patients and reduce disability and mortality. Inhibition of TNF- $\alpha$ activity agents was firstly confirmed as the biologic drugs for RA treatment when conventional disease modified antirheumatic drugs (DMARDs) had no effect on reducing the disease activity [24]. Until now, lots of blockage of TNF$\alpha$ activity agents were approved in the clinical use, which were divided into two categories, anti-TNF- $\alpha$ antibody and soluble TNF- $\alpha$ receptor [25]. Furthermore, other biologics were explored and licensed for the clinical use of RA [22], for instance, IL-6, a representative cytokine featuring pleiotropic activity and redundancy. However, uncontrolled persistent production of IL-6 leads to the development of rheumatoid arthritis (RA). Tocilizumab, a humanized anti-IL-6 receptor antibody, has proved its efficacy and tolerable safety either as monotherapy or in combination with DMARDs [26].

RA leads not only to the destruction of cartilage and bone but also to system damage including cardiovascular, pulmonary, and endocrine system [27, 28]. This demonstrated a relationship between inflammatory factors and insulin resistance [29-31]. Consistently, there are increased levels of serum inflammatory markers, IL-6, in patients with type 2 diabetes, which can induce beta-cell apoptosis [19, 31-33]. Our previous study also showed that the abnormal glucose metabolism was accompanied by the increased IL6 expression [34]. Furthermore, in line with increased IL-6 expression, the apoptosis related enzyme Caspase- 3 was also markedly increased in $\beta$ cell. In addition, TNF- $\alpha$ produced by adipose tissue macrophage was widely regarded as the critical pathogenic factor in type 2 diabetes. The prevalence of RA patients with diabetes is about $15 \%-19 \%$, which is significantly higher than the global incidence rate $[1,35]$. The long-term systemic inflammatory status in RA patients might be the cause of islet $\beta$ cell damage in RA patients.

\section{RA and Abnormal Glucose Metabolism}

RA patients often showed impaired $\beta$ cell function and insulin sensitivity [36]. Dessein and Joffe found that the higher degree of inflammation (high sensitive CRP > $1.92 \mathrm{mg} / \mathrm{L}$ ) was in negative correlation with the low degree of inflammation (high sensitive CRP $<1.92 \mathrm{mg} / \mathrm{L}$ ) in patients with higher levels of HOMA-IR. However, there was no significant difference between HOMA- $\beta$ levels. These data suggested that the degree of inflammation played an important effect in the progression of IR in RA patients [37]. Besides, Chung et al. reported that the prevalence of metabolic syndrome in patients with RA (42\% of long-term patients, patients with early 31\%) was significantly higher than the non-RA group (11\%) and also found that CRP and ESR were significantly positively correlated with the homocysteine levels in patients with RA [38]. Furthermore, Chung et al. reported that when adjustment for age, sex, race, BMI, and current use of glucocorticoids (GC) was performed, the HOMA-IR levels of patients with RA were also significantly higher in patients with SLE [39]. Nevertheless, the HOMA-IR was significantly positively correlated with IL-6 (correlation coefficient $r=0.63)$ and TNF- $\alpha(r=0.50)$ in patients with RA; the decreased insulin sensitivity might be due to inflammatory cytokines in RA. A study showed that $72 \%$ of early RA patients were accompanied with insulin resistance, and the HOMA-IR of RA patient group was significantly increased compared to the age- and sex-matched control group $[29,30]$.

RA patients without diagnosed DM frequently performed glucose tolerance test, and these results demonstrated an increased HOMA-IR index, decreased insulin sensitivity, and reduced dynamic insulin secretion index and disposition 
index in RA patients when compared with general population [4]. These data suggested that the early insulin secretion damaged $\beta$ cell after glucose stimulation. On the contrary, it also demonstrated that the HOMA- $\beta$ levels were higher in RA patients [40]. The reason is that, in order to maintained normal fasting blood glucose levels, RA patients secreted more insulin and induced an increased HOMA- $\beta$ index. Therefore, the HOMA- $\beta$ index increase did not mean improvement of $\beta$ cell function but merely to compensate for the insulin sensitivity decreases. Similarly, Ferraz-Amaro et al. also detected insulin, C-peptide, and split and intact proinsulin in the RA patients and found that, in RA patients, HOMA-IR levels were significantly higher $[36,37]$. Even with the exclusion of taking GC in RA patients, the results were not changed. Furthermore, in RA patients, the proportion of proinsulin was significantly higher than the control group; it might be due to proinsulin process failing to process under the systemic inflammatory state [41-44]. Taken together, this suggested that $\beta$ cell function in RA patients had been damaged.

The above studies of RA patients with $\beta$ cell dysfunction described a clarified relation between the systemic inflammatory state and abnormal glucose metabolism. Recently, studies had shown that IR and $\beta$ cell function were improved after the anti-TNF therapy of RA patients, and the prevalence of DM of RA patients with biologics was significantly decreased when compared with patients with other antirheumatic drugs treatment [45-48]. These data supported the relationship between inflammation and abnormal glucose metabolism. Additionally, the use of anti-TNF agents therapy in active RA patients with IR, the fasting blood glucose, insulin levels, and IR index were improved after the anti-TNF therapy [49-53]. These findings revealed that the TNF- $\alpha$ might be the critical pathogenic cytokine in the development of IR in RA patients. By analyzing the serine ${ }^{312}$ phosphorylated form $\left(\mathrm{p}-\mathrm{Ser}^{312}\right)$ of IRS-1 and activation with phosphorylation of protein kinase (AKT) variations before and after anti-TNF therapy in RA patients, the mechanisms of its improvement in RA patients with IR might be due to $\mathrm{p}$-Ser ${ }^{312}$ IRS-1 levels decreasing and the proportion of activation with phosphorylation of AKT increasing after the anti-TNF therapy [45].

\section{The Influence of Liver in Abnormal Glucose Metabolism in RA}

In addition to articular cartilage injury, RA also leads to significant pathogenic changes in other organs such as lung, vascular tissue, liver, and muscle [54-57]. The liver is an important organ participating in glucose metabolism, including the storage, distribution, and regulation of organismic blood glucose. There are multiple pathways of glucose metabolism existing in the liver and some of them are unique to it [58]. RA can lead to a variety of liver lesions and then result in abnormal glucose metabolism. Several studies have shown that the reactive oxygen species (ROS) participate in the generation of RA $[59,60]$. High level of ROS in the liver of adjuvant-induced arthritis in rats seems to be resulting from both a deficient antioxidant defense and a stimulated prooxidant system $[61,62]$. It has been reported that the livers of collagen induced arthritis rats exhibited a higher oxygen consumption, and the efficiency of mitochondrial energy transduction did not decrease [63]. The activity of NADPH2-oxidase enzyme and N-demethylase and the levels of cytochrome P-450 in the liver microsomal of adjuvant arthritic rats are significantly reduced $[64,65]$, indicating that the capability of formation of $\beta$-glucuronide conjugates and oxidative metabolism of exogenous compounds and steroids are reduced. A study also demonstrated that the reduced availability of equivalents in cytosol and the lower catalytic activities of key enzymes phosphoenolpyruvate inhibited hepatic gluconeogenesis in arthritic rats [66]. The higher activities of glucokinase and the lower activities of hepatic mitochondrial pyruvate dehydrogenase lead to increasing the uptake of hepatic glucose and the rates of glycolysis in livers of arthritic rats [67]. The systemic inflammation induced by adjuvant can cause lysosomes and mitochondria irregularly shaped and result in hepatic transaminases of the plasma with higher activities and hepatocellular morphology changes [68]. In conclusion, RA can lead to liver dysfunction and affect glucose metabolism which might result in abnormal glucose metabolism.

\section{RA Patients Using GC with Abnormal Glucose Metabolism}

Glucocorticoids (GC) was a common drug in RA treatment, but its exerts a side effect on the metabolism of RA patients [69]. In the normal population of the clinical observation study, it is found that GC treatment reduced liver and peripheral insulin sensitivity and destruction of $\beta$ cell function [70]. Furthermore, a recent study has shown that RA patients treated with oral GC are an important risk factor for DM; a $25-30 \%$ increased risk of DM occurrence was related to each additional $5 \mathrm{mg}$ current oral GCs, while only the GC doses taken persistently for 6 months are closely associated with the risk of DM [71]. The administration of GC reduced fasting insulin sensitivity in the cross-sectional study of RA patients $[4,72]$. Additionally, the use of GC was mainly related to IR among women, and RA patients without other metabolic risk factors treated with low dose of GC do not lead to abnormal glucose metabolism [73]. A randomized and double-blind study also found that oral glucose tolerance test inspection after a week of the glucose metabolism did not show changes from before treatment; this situation might be because the GC itself causes abnormal glucose metabolism action offset by improving glucose metabolism in patients through antiinflammation and disease action improvement [74]. Meanwhile, a clinical study also showed that a deterioration in glucose metabolism patients after GC treatment generally had a longer duration than before treatment; this is consistent with the aforementioned that extension of inflammatory state could increase insulin sensitivity and negative effects of $\beta$ cell function [75]. The mechanism might be due to the fact that GC could further undermine the long course of RA patients where $\beta$ cell dysfunction was observed. Although there are so many studies on the glucose metabolism of GC in RA patients, it still needs long-term clinical trials to study the long-term use of GC in RA patients induced diabetic effects. 


\section{Conclusion}

In summary, the systemic inflammation in RA patients played an important effect in the glucose metabolism, and the longterm inflammatory status could lead to $\beta$ cell dysfunction and apoptosis and affect the liver and hepatic glucose metabolism pathway. Besides, the drug used in the RA treatment, such as GC, had a certain influence on glucose metabolism. Therefore, the abnormal glucose metabolism in the development of RA should be paid attention, and its mechanisms need to be further explored.

\section{Conflicts of Interest}

The authors declare no conflicts of interest regarding the publication of this paper.

\section{Authors' Contributions}

Hui Pi and Haotong Zhou contributed equally to this work.

\section{Acknowledgments}

This project was supported by the Jiangxi Provincial Science and Technology Department (20112BBG70040).

\section{References}

[1] J. F. Simard and M. A. Mittleman, "Prevalent rheumatoid arthritis and diabetes among NHANES III participants aged 60 and older," Journal of Rheumatology, vol. 34, no. 3, pp. 469-473, 2007.

[2] S. Wild, G. Roglic, A. Green, R. Sicree, and H. King, "Global Prevalence of Diabetes: estimates for the year 2000 and projections for 2030," Diabetes Care, vol. 27, no. 5, pp. 1047-1053, 2004.

[3] D. H. Solomon, T. J. Love, C. Canning, and S. Schneeweiss, "Risk of diabetes among patients with rheumatoid arthritis, psoriatic arthritis and psoriasis," Annals of the Rheumatic Diseases, vol. 69, no. 12, pp. 2114-2117, 2010.

[4] J. N. Hoes, M. C. Van Der Goes, D. H. Van Raalte et al., "Glucose tolerance, insulin sensitivity and $\beta$-cell function in patients with rheumatoid arthritis treated with or without low-to-medium dose glucocorticoids," Annals of the Rheumatic Diseases, vol. 70, no. 11, pp. 1887-1894, 2011.

[5] G. S. Hotamisligil, "Inflammation and metabolic disorders," Nature, vol. 444, no. 7121, pp. 860-867, 2006.

[6] J. Jurčovičová, A. Štofková, M. Škurlová, M. Baculíková, Š. Zórad, and M. Stančíková, "Alterations in adipocyte glucose transporter GLUT4 and circulating adiponectin and visfatin in rat adjuvant induced arthritis," General Physiology and Biophysics, vol. 29, no. 1, pp. 79-84, 2010.

[7] M. J. Ormseth, L. L. Swift, S. Fazio et al., "Free fatty acids are associated with insulin resistance but not coronary artery atherosclerosis in rheumatoid arthritis," Atherosclerosis, vol. 219, no. 2, pp. 869-874, 2011.

[8] J. Jager, T. Grémeaux, M. Cormont, Y. Le Marchand-Brustel, and J.-F. Tanti, "Interleukin- $1 \beta$-induced insulin resistance in adipocytes through down-regulation of insulin receptor substrate1 expression," Endocrinology, vol. 148, no. 1, pp. 241-251, 2007.
[9] J. Yang, C. Wang, and Y. Guan, "Cytokines in the progression of pancreatic $\beta$-cell dysfunction," International Journal of Endocrinology, vol. 2010, Article ID 515136, 10 pages, 2010.

[10] A. Kiely, N. H. McClenaghan, P. R. Flatt, and P. Newsholme, "Pro-inflammatory cytokines increase glucose, alanine and triacylglycerol utilization but inhibit insulin secretion in a clonal pancreatic $\beta$-cell line," Journal of Endocrinology, vol. 195, no. 1, pp. 113-123, 2007.

[11] J. Yang, Y. Chi, B. R. Burkhardt, Y. Guan, and B. A. Wolf, "Leucine metabolism in regulation of insulin secretion from pancreatic beta cells," Nutrition Reviews, vol. 68, no. 5, pp. 270 279, 2010.

[12] D. K. C. Cooper and R. Bottino, "Recent advances in understanding xenotransplantation: implications for the clinic," Expert Review of Clinical Immunology, vol. 11, no. 12, pp. 13791390, 2015.

[13] G. Papaccio, A. Graziano, R. D’Aquino, S. Valiante, and F. Naro, "A biphasic role of nuclear transcription factor (NF) $-\kappa \mathrm{B}$ in the islet $\beta$-cell apoptosis induced by interleukin (IL)- $1 \beta$," Journal of Cellular Physiology, vol. 204, no. 1, pp. 124-130, 2005.

[14] M.-Y. Song, E.-K. Kim, W.-S. Moon et al., "Sulforaphane protects against cytokine- and streptozotocin-induced $\beta$-cell damage by suppressing the NF- $\kappa \mathrm{B}$ pathway," Toxicology and Applied Pharmacology, vol. 235, no. 1, pp. 57-67, 2009.

[15] E. N. Gurzov, F. Ortis, D. A. Cunha et al., "Signaling by IL$1 \beta+$ IFN $-\gamma$ and ER stress converge on DP5/Hrk activation: a novel mechanism for pancreatic $\beta$-cell apoptosis," Cell Death and Differentiation, vol. 16, no. 11, pp. 1539-1550, 2009.

[16] Q. Wang, H. Zhang, B. Zhao, and H. Fei, "IL-1 $\beta$ caused pancreatic $\beta$-cells apoptosis is mediated in part by endoplasmic reticulum stress via the induction of endoplasmic reticulum $\mathrm{Ca} 2+$ release through the c-Jun N-terminal kinase pathway," Molecular and Cellular Biochemistry, vol. 324, no. 1-2, pp. 183190, 2009.

[17] O. Osborn, S. E. Brownell, M. Sanchez-Alavez, D. Salomon, H. Gram, and T. Bartfai, "Treatment with an Interleukin 1 beta antibody improves glycemic control in diet-induced obesity," Cytokine, vol. 44, no. 1, pp. 141-148, 2008.

[18] G. Lacraz, M.-H. Giroix, N. Kassis et al., "Islet endothelial activation and oxidative stress gene expression is reduced by IL1 Ra treatment in the type 2 diabetic GK rat," PLoS ONE, vol. 4, no. 9, article e6963, 2009.

[19] S. Kim, K. A. Kim, K. Suk et al., "Apoptosis of human islet cells by cytokines," Immune Network, vol. 12, no. 3, pp. 113-117, 2012.

[20] K. Suk, S. Kim, Y.-H. Kim et al., "IFN- $\gamma /$ TNF- $\alpha$ synergism as the final effector in autoimmune diabetes: a key role for STAT1/IFN regulatory factor-1 pathway in pancreatic/ $\beta$ cell death," Journal of Immunology, vol. 166, no. 7, pp. 4481-4489, 2001.

[21] I. B. McInnes, C. D. Buckley, and J. D. Isaacs, "Cytokines in rheumatoid arthritis-shaping the immunological landscape," Nature Reviews Rheumatology, vol. 12, no. 1, pp. 63-68, 2016.

[22] A. Calabrò, A. L. Caterino, E. Elefante et al., "One year in review 2016: novelties in the treatment of rheumatoid arthritis," Clinical and Experimental Rheumatology, vol. 34, no. 3, pp. 357-372, 2016.

[23] F. Iannone, G. Lopalco, D. Rigante, I. Orlando, L. Cantarini, and G. Lapadula, "Impact of obesity on the clinical outcome of rheumatologic patients in biotherapy," Autoimmunity Reviews, vol. 15, no. 5, pp. 447-450, 2016.

[24] G. S. Hazlewood, C. Barnabe, G. Tomlinson, D. Marshall, D. Devoe, and C. Bombardier, "Methotrexate monotherapy 
and methotrexate combination therapy with traditional and biologic disease modifying antirheumatic drugs for rheumatoid arthritis: abridged cochrane Systematic review and network meta-analysis," BMJ (Online), vol. 353, article il777, 2016.

[25] C. C. Mok, W. C. Tsai, D. Y. Chen, and J. C. C. Wei, "Immunogenicity of anti-TNF biologic agents in the treatment of rheumatoid arthritis," Expert Opinion on Biological Therapy, vol. 16, no. 2, pp. 201-211, 2016.

[26] X. Liu, A. J. Teichtahl, and I. P. Wicks, "Interleukin-6 in rheumatoid arthritis - From the laboratory to the bedside," Current Pharmaceutical Design, vol. 21, no. 17, pp. 2187-2197, 2015.

[27] H. Maradit-Kremers, P. J. Nicola, C. S. Crowson, K. V. Ballman, and S. E. Gabriel, "Cardiovascular death in rheumatoid arthritis: A population-based study," Arthritis and Rheumatism, vol. 52, no. 3, pp. 722-732, 2005.

[28] A. A. Wagan, T. E. Haque Mahmud, A. Rasheed, Z. A. Zafar, A. U. Rehman, and A. Ali, "Cardiovascular risk score in Rheumatoid arthritis," Pakistan Journal of Medical Sciences, vol. 32, no. 3, pp. 534-538, 2016.

[29] S. Manrique-Arija, I. Ureña, P. Valdivielso et al., "Insulin resistance and levels of adipokines in patients with untreated early rheumatoid arthritis," Clinical Rheumatology, vol. 35, no. 1, pp. 43-53, 2016.

[30] D. Shahin, E. Eltoraby, A. Mesbah, and M. Houssen, "Insulin resistance in early untreated rheumatoid arthritis patients," Clinical Biochemistry, vol. 43, no. 7-8, pp. 661-665, 2010.

[31] B. Fève and J.-P. Bastard, "The role of interleukins in insulin resistance and type 2 diabetes mellitus," Nature Reviews Endocrinology, vol. 5, no. 6, pp. 305-311, 2009.

[32] Y. S. Oh, Y.-J. Lee, E. Y. Park, and H.-S. Jun, "Interleukin6 treatment induces beta-cell apoptosis via STAT-3-mediated nitric oxide production," Diabetes/Metabolism Research and Reviews, vol. 27, no. 8, pp. 813-819, 2011.

[33] C. A. Delaney, D. Pavlovic, A. Hoorens, D. G. Pipeleers, and D. L. Eizirik, "Cytokines induce deoxyribonucleic acid strand breaks and apoptosis in human pancreatic islet cells," Endocrinology, vol. 138, no. 6, pp. 2610-2614, 1997.

[34] H. Jin, Y. Ning, H. Zhou, and Y. Wang, "IL-6 promotes islet beta-cell dysfunction in rat collagen-induced arthritis," Journal of Diabetes Research, vol. 2016, Article ID 7592931, 6 pages, 2016.

[35] Ö. N. Pamuk, E. Ünlü, and N. Çakir, "Role of insulin resistance in increased frequency of atherosclerosis detected by carotid ultrasonography in rheumatoid arthritis," Journal of Rheumatology, vol. 33, no. 12, pp. 2447-2452, 2006.

[36] I. Ferraz-Amaro, J. A. Garcia-Dopico, L. Medina-Vega, M. A. Gonzalez-Gay, and F. Diaz-Gonzalez, "Impaired beta cell function is present in nondiabetic rheumatoid arthritis patients," in Arthritis Research \& Therapy, vol. 15, article R17, 2013.

[37] P. H. Dessein and B. I. Joffe, "Insulin resistance and impaired beta cell function in rheumatoid arthritis," Arthritis and Rheumatism, vol. 54, no. 9, pp. 2765-2775, 2006.

[38] C. P. Chung, A. Oeser, J. F. Solus et al., "Prevalence of the metabolic syndrome is increased in rheumatoid arthritis and is associated with coronary atherosclerosis," Atherosclerosis, vol. 196, no. 2, pp. 756-763, 2008.

[39] C. P. Chung, A. Oeser, J. F. Solus et al., "Inflammationassociated insulin resistance: differential effects in rheumatoid arthritis and systemic lupus erythematosus define potential mechanisms," Arthritis and Rheumatism, vol. 58, no. 7, pp. 21052112, 2008.
[40] J. T. Giles, S. Danielides, M. Szklo et al., "Insulin resistance in rheumatoid arthritis: disease-related indicators and associations with the presence and progression of subclinical atherosclerosis," Arthritis and Rheumatology, vol. 67, no. 3, pp. 626-636, 2015.

[41] D. Jain, G. Weber, D. Eberhard et al., "DJ-1 protects pancreatic beta cells from cytokine- and streptozotocin-mediated cell death," PLoS ONE, vol. 10, no. 9, Article ID e0138535, 2015.

[42] L. A. Berchtold, M. Prause, J. Størling, and T. Mandrup-Poulsen, "Cytokines and Pancreatic $\beta$-Cell Apoptosis," Advances in Clinical Chemistry, pp. 99-158, 2016.

[43] J. Barthson, C. M. Germano, F. Moore et al., "Cytokines tumor necrosis factor- $\alpha$ and interferon- $\gamma$ induce pancreatic $\beta$-cell apoptosis through STAT1-mediated bim protein activation," Journal of Biological Chemistry, vol. 286, no. 45, pp. 3963239643, 2011.

[44] E. N. Gurzov, C. M. Germano, D. A. Cunha et al., "p53 upregulated modulator of apoptosis (PUMA) activation contributes to pancreatic $\beta$-cell apoptosis induced by proinflammatory cytokines and endoplasmic reticulum stress," Journal of Biological Chemistry, vol. 285, no. 26, pp. 19910-19920, 2010.

[45] I. Stagakis, G. Bertsias, S. Karvounaris et al., "Anti-tumor necrosis factor therapy improves insulin resistance, beta cell function and insulin signaling in active rheumatoid arthritis patients with high insulin resistance," Arthritis Research and Therapy, vol. 14, no. 3, article R141, 2012.

[46] F. C. Huvers, C. Popa, M. G. Netea, F. H. J. Van Den Hoogen, and C. J. Tack, "Improved insulin sensitivity by anti-TNF $\alpha$ antibody treatment in patients with rheumatic diseases," Annals of the Rheumatic Diseases, vol. 66, no. 4, pp. 558-559, 2007.

[47] D. H. Solomon, E. Massarotti, R. Garg, J. Liu, C. Canning, and S. Schneeweiss, "Association between disease-modifying antirheumatic drugs and diabetes risk in patients with rheumatoid arthritis and psoriasis," JAMA-Journal of the American Medical Association, vol. 305, no. 24, pp. 2525-2531, 2011.

[48] J. L. Antohe, A. Bili, J. A. Sartorius et al., "Diabetes mellitus risk in rheumatoid arthritis: reduced incidence with anti-tumor necrosis factor $\alpha$ therapy," Arthritis Care and Research, vol. 64, no. 2, pp. 215-221, 2012.

[49] M. C. Oliveira, L. P. Tavares, J. P. Vago et al., "Tumor necrosis factor, but not neutrophils, alters the metabolic profile in acute experimental arthritis," PLoS ONE, vol. 11, no. 1, Article ID e0146403, 2016.

[50] N. Maruotti, F. d'Onofrio, and F. P. Cantatore, "Metabolic syndrome and chronic arthritis: effects of anti-TNF- $\alpha$ therapy," Clinical and Experimental Medicine, vol. 15, no. 4, pp. 433-438, 2014.

[51] C.-Y. Chen, C.-Y. Tsai, P.-C. Lee, and S.-D. Lee, "Long-term etanercept therapy favors weight gain and ameliorates cachexia in rheumatoid arthritis patients: Roles of gut hormones and leptin," Current Pharmaceutical Design, vol. 19, no. 10, pp. 19561964, 2013.

[52] J. A. Miranda-Filloy, J. Llorca, B. Carnero-Lopez, C. GonzalezJuanatey, R. Blanco, and M. A. Gonzalez-Gay, "TNF-alpha antagonist therapy improves insulin sensitivity in non-diabetic ankylosing spondylitis patients," Clinical and Experimental Rheumatology, vol. 30, pp. 850-855, 2012.

[53] M. A. Gonzalez-Gay, J. M. De Matias, C. Gonzalez-Juanatey et al., "Anti-tumor necrosis factor- $\alpha$ blockade improves insulin resistance in patients with rheumatoid arthritis," Clinical and Experimental Rheumatology, vol. 24, no. 1, pp. 83-86, 2006. 
[54] O. Sangha, "Epidemiology of rheumatic diseases," Rheumatology, vol. 39, no. 2, pp. 3-12, 2000.

[55] N. Sattar, D. W. McCarey, H. Capell, and I. B. McInnes, "Explaining how "high-grade" systemic inflammation accelerates vascular risk in rheumatoid arthritis," Circulation, vol. 108, no. 24, pp. 2957-2963, 2003.

[56] Y. Haruna, Y. Morita, N. Komai et al., "Endothelial dysfunction in rat adjuvant-induced arthritis: Vascular superoxide production by $\mathrm{NAD}(\mathrm{P}) \mathrm{H}$ oxidase and uncoupled endothelial nitric oxide synthase," Arthritis and Rheumatism, vol. 54, no. 6, pp. 1847-1855, 2006.

[57] Y. Haruna, Y. Morita, T. Yada, M. Satoh, D. A. Fox, and N. Kashihara, "Fluvastatin reverses endothelial dysfunction and increased vascular oxidative stress in rat adjuvant-induced arthritis," Arthritis and Rheumatism, vol. 56, no. 6, pp. 18271835, 2007.

[58] T. Ueno and M. Komatsu, "Autophagy in the liver: functions in health and disease," Gastroenterology \& Hepatology, vol. 14, pp. 170-184, 2017.

[59] A. Kamanli, M. Naziroğlu, N. Aydilek, and C. Hacievliyagil, "Plasma lipid peroxidation and antioxidant levels in patients with rheumatoid arthritis," Cell Biochemistry and Function, vol. 22, no. 1, pp. 53-57, 2004.

[60] A. Seven, S. Güzel, M. Aslan, and V. Hamuryudan, "Lipid, protein, DNA oxidation and antioxidant status in rheumatoid arthritis," Clinical Biochemistry, vol. 41, no. 7-8, pp. 538-543, 2008.

[61] G. De Almeida Gonçalves, A. B. De Sá-Nakanishi, M. M. Wendt et al., "Green tea extract improves the oxidative state of the liver and brain in rats with adjuvant-induced arthritis," Food and Function, vol. 6, no. 8, pp. 2701-2711, 2015.

[62] J. F. Comar, A. Babeto De Sá-Nakanishi, A. L. De Oliveira et al., "Oxidative state of the liver of rats with adjuvant-induced arthritis," Free Radical Biology and Medicine, vol. 58, pp. 144153, 2013.

[63] S. M. Caparroz-Assef, C. A. Bersani-Amado, É. A. Do Nascimento, A. M. Kelmer-Bracht, and E. L. Ishii-Iwamoto, "Effects of the nonsteroidal anti-inflammatory drug nimesulide on energy metabolism in livers from adjuvant-induced arthritic rats," Research Communications in Molecular Pathology and Pharmacology, vol. 99, no. 1, pp. 93-116, 1998.

[64] H. Sanada, M. Sekimoto, A. Kamoshita, and M. Degawa, "Changes in expression of hepatic cytochrome P450 subfamily enzymes during development of adjuvant-induced arthritis in rats," Journal of Toxicological Sciences, vol. 36, no. 2, pp. 181-190, 2011.

[65] D. M. Morton and D. H. Chatfield, "The effects of adjuvantinduced arthritis on the liver metabolism of drugs in rats," Biochemical Pharmacology, vol. 19, no. 2, pp. 473-481, 1970.

[66] Z. Fedatto, E. L. Ishii-Iwamoto, C. B. Amado et al., "Gluconeogenesis in the liver of arthritic rats," Cell Biochemistry and Function, vol. 17, no. 4, pp. 271-278, 1999.

[67] Z. Fedatto Jr., E. L. Ishii-Iwamoto, C. Bersani-Amado, E. R. M. Maciel, A. Bracht, and A. M. Kelmer-Bracht, "Glucose phosphorylation capacity and glycolysis in the liver of arthritic rats," Inflammation Research, vol. 49, no. 3, pp. 128-132, 2000.

[68] D. Y. Hung, G. A. Siebert, P. Chang et al., "Hepatic pharmacokinetics of propranolol in rats with adjuvant-induced systemic inflammation," American Journal of Physiology-Gastrointestinal and Liver Physiology, vol. 290, no. 2, pp. G343-G351, 2006.

[69] J. W. J. Bijlsma and F. Buttgereit, "Adverse events of glucocorticoids during treatment of rheumatoid arthritis: lessons from cohort and registry studies," Rheumatology, vol. 55, pp. ii3-ii5, 2016.

[70] D. H. Van Raalte, V. Nofrate, M. C. Bunck et al., "Acute and 2week exposure to prednisolone impair different aspects of $\beta$-cell function in healthy men," European Journal of Endocrinology, vol. 162, no. 4, pp. 729-735, 2010.

[71] M. Movahedi, M.-E. Beauchamp, M. Abrahamowicz et al., "Risk of incident diabetes mellitus associated with the dosage and duration of oral glucocorticoid therapy in patients with rheumatoid arthritis," Arthritis and Rheumatology, vol. 68, no. 5, pp. 1089-1098, 2016.

[72] P. H. Dessein, B. I. Joffe, A. E. Stanwix, B. F. Christian, and M. Veller, "Glucocorticoids and insulin sensitivity in rheumatoid arthritis," The Journal of Rheumatology, vol. 31, no. 5, pp. 867874, 2004.

[73] A. Penesova, Z. Radikova, M. Vlcek et al., "Chronic inflammation and low-dose glucocorticoid effects on glucose metabolism in premenopausal females with rheumatoid arthritis free of conventional metabolic risk factors," Physiological Research, vol. 62, pp. 75-83, 2013.

[74] D. Den Uyl, D. H. Van Raalte, M. T. Nurmohamed et al., "Metabolic effects of high-dose prednisolone treatment in early rheumatoid arthritis: Balance between diabetogenic effects and inflammation reduction," Arthritis and Rheumatism, vol. 64, no. 3, pp. 639-646, 2012.

[75] C. M. Spies, R. H. Straub, M. Cutolo, and F. Buttgereit, "Circadian rhythms in rheumatology-a glucocorticoid perspective," Arthritis Research \& Therapy, vol. 16, article S3, supplement 2, 2014. 


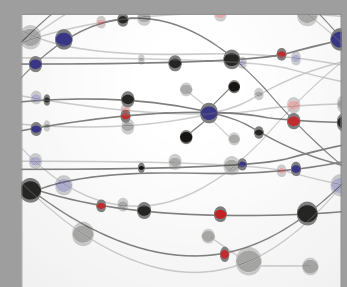

The Scientific World Journal
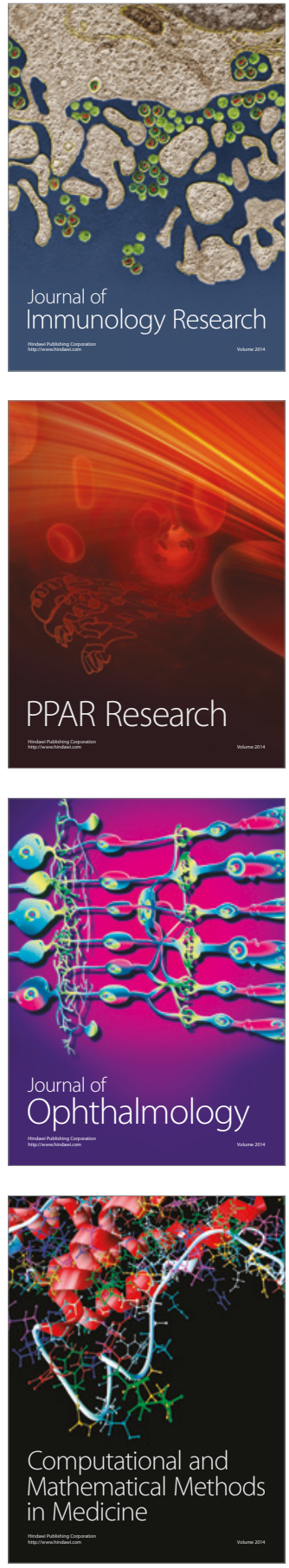

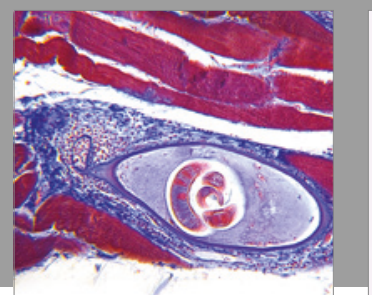

Gastroenterology Research and Practice
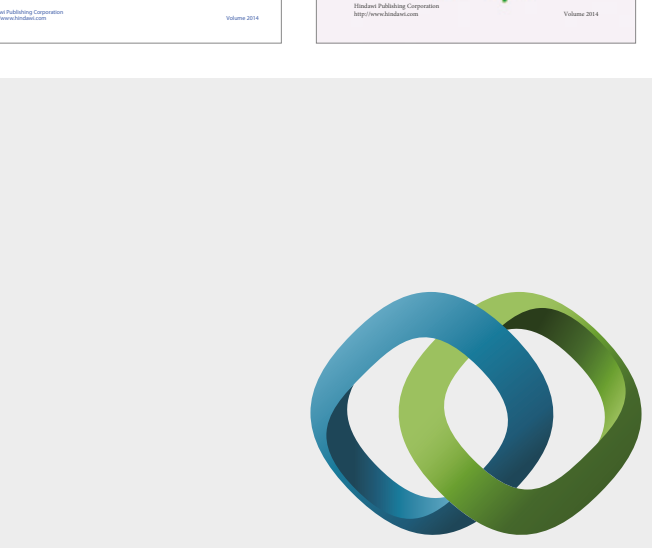

\section{Hindawi}

Submit your manuscripts at

https://www.hindawi.com
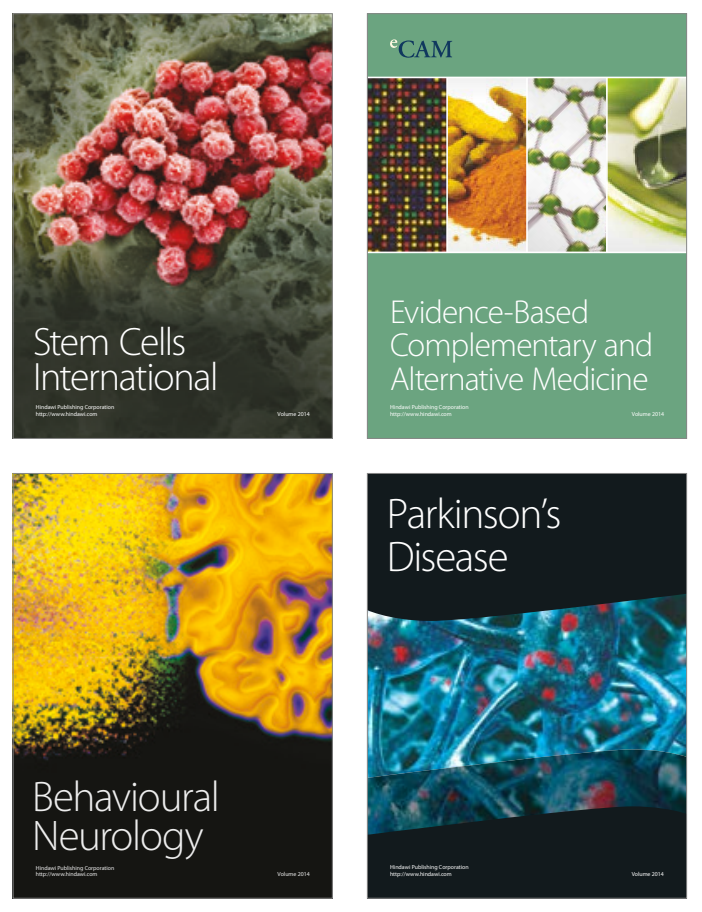
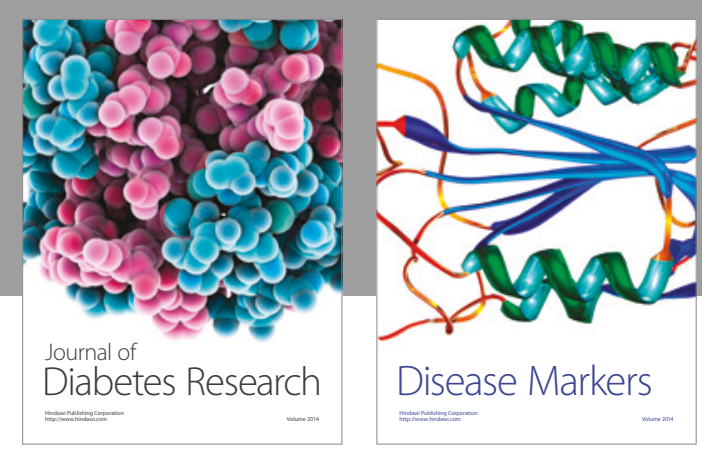

Disease Markers
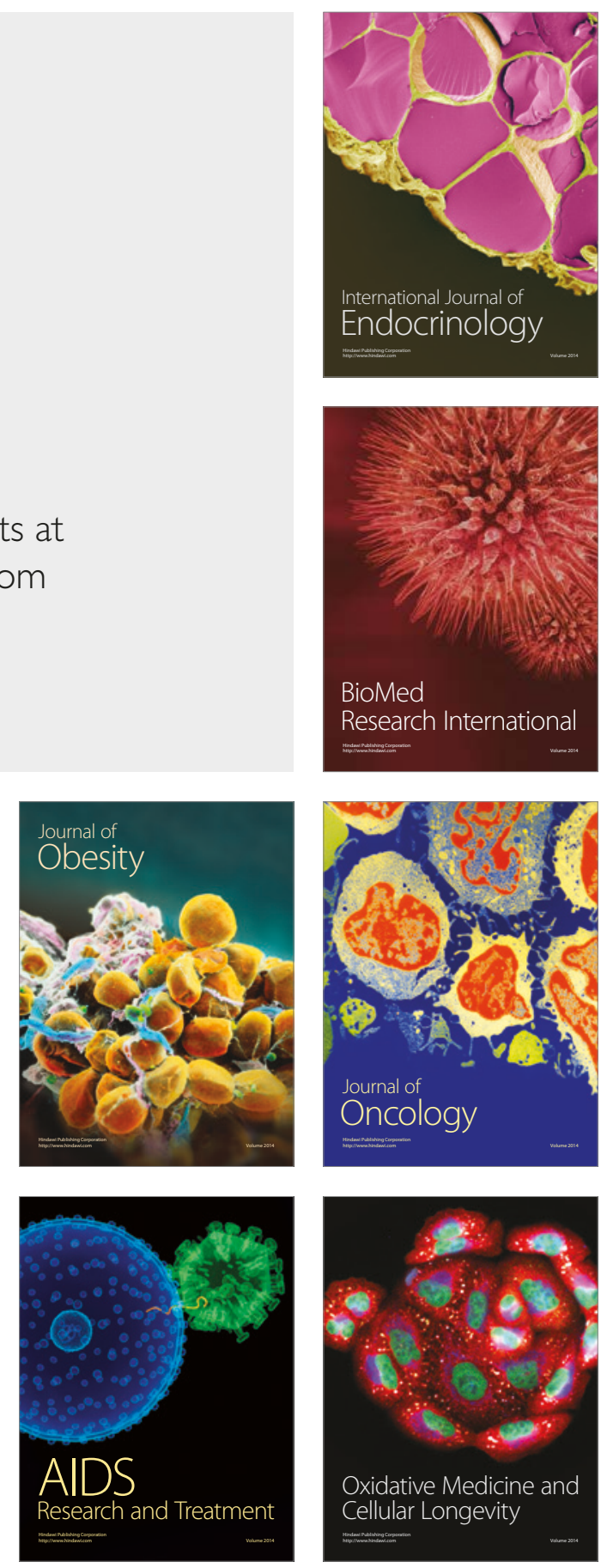